\title{
Effect of Hydroalcholic Extract of Nigella sativa on Doxorubicin-Induced Functional Damage of Kidney in Rats
}

\author{
Mohebbati R. ${ }^{1}$ MSc, Abbsnezhad A. ${ }^{2}$ PhD, Khajavi Rad A.* ${ }^{*} D, P h D$, \\ Mousavi S.M. ${ }^{1}$ MSc, Haghshenas M. ${ }^{1}$ MSc
}

\begin{abstract}
*Physiology Department, Medicine Faculty, Mashhad University of Medical Sciences, Mashhad, Iran 1Physiology Department, Medicine Faculty, Mashhad University of Medical Sciences, Mashhad, Iran ${ }^{2}$ Basic Sciences Department, Medicine Faculty, Gonabad University of Medical Sciences, Gonabad, Iran
\end{abstract}

\begin{abstract}
Aims: Doxorubicin is an important anti-cancer drug which can cause renal toxicity. Nigella sativa has anti-inflammatory and antioxidant effects. The aim of this study was to determine the effects of hydroalcoholic extract of Nigella sativa on doxorubicin-induced functional damage of kidney in rats.

Materials \& Methods: This experimental study was implemented, using 32 male Wistar rats which were divided randomly into 4 groups; control, doxorubicin $(5 \mathrm{mg} / \mathrm{kg})$, Nigella sativa extract $(200 \mathrm{mg} / \mathrm{kg})$ and Nigella sativa plus doxorubicin. The groups were treated for 5 consecutive weeks and on days $0,6,10,14,21,28,35$; the 24-hour urine samples and serum were collected to measure the levels of serum and urine glucose, serum urea, urea clearance and Glomerular Filtration Rate. Statistical analyses were made using one-way ANOVA followed by the Tukey's test and paired T test.

Findings: The mean of serum urea on day 10 in doxorubicin group was significantly increased compared to the pre-injection state. The mean of urine glucose on day 28 in Nigella sativa plus doxorubicin group was significantly decreased compared to doxorubicin group. The means of GFR on days 21 and 35 in doxorubicin group were significantly decreased compared to control day. The means of GFR on days 21, 28, 35 in Nigella sativa plus doxorubicin group were significantly increased compared to doxorubicin group. The means of glucose on days 21 and 28 in doxorubicin group were significantly decreased compared to control day.

Conclusion: The hydroalcoholic extract of Nigella sativa reduces the doxorubicin-induced functional damage of kidney in rats and helps improve the Glomerular Filtration Rate rate and decreases the glucosuria.

\section{Keywords}

Nigella sativa [http://www.ncbi.nlm.nih.gov/mesh/68031881];

Renal Insufficiency [http://www.ncbi.nlm.nih.gov/mesh/68051437];

Doxorubicin [http://www.ncbi.nlm.nih.gov/mesh/68004317];

Glomerular Filtration Rate [http://www.ncbi.nlm.nih.gov/mesh/68005919];

Glucosuria [http://www.ncbi.nlm.nih.gov/mesh/68006029]
\end{abstract}

\footnotetext{
${ }^{*}$ Corresponding Author

Tel: +985138828565

Fax: +985138828564

Address: Department of Physiology, School of Medicine, Mashhad University of Medical Sciences, Azadi Square, Mashhad, Iran. Postal Code: 917794-8564

khajavirada@mums.ac.ir

Received: May 30, 2015 
مقدمه

نفروياتى يكى از علل مرگومير بوده كه شيوع آن در جهان در حال افزايش است. نفروياتى عبارت است از كاهش نسبى عملكرد كليه

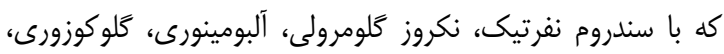

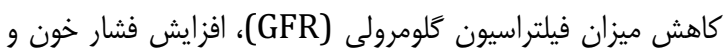

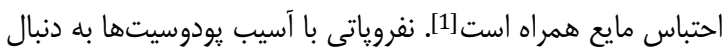

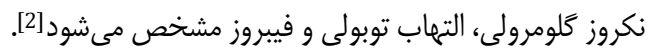

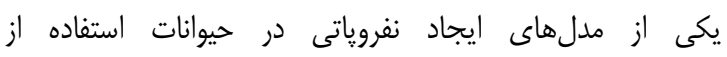

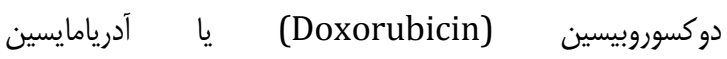
فاست. دوكسوروبيسين از آنتىبيوتيكهاى (Adriamycin) ضدسرطان بوده و در بسيارى از سرطانها مانند سرطان مثانه،

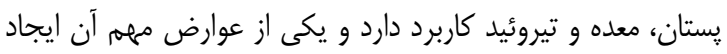
نفروياتى است] [1]. دوكسوروبيسين سبب افزايش دفع N-1ستيل ملوگز آمين (NAG)،

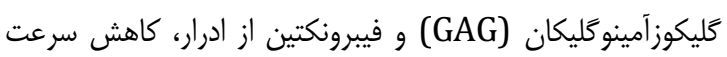

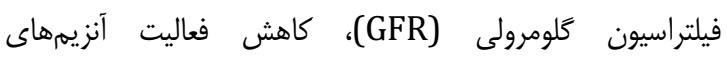

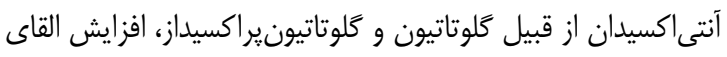

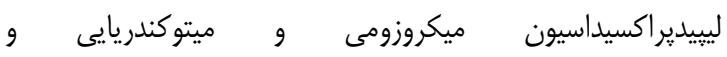

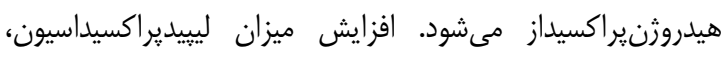

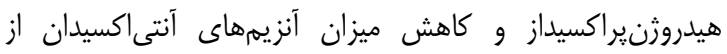
مهمترين علل آسيب اكسيداتيو كليوى هستند [3,4). سياهدانه (Nigella sativa) از خانواده آلاله (رانونكولاسه)، گياهى دارويى است كه بلهور وسيع براى مقاصد درمانى مورد

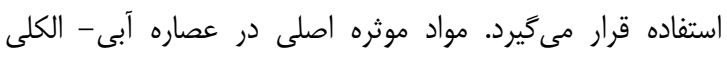
سياهدانه، تيموكينون (بيشترين فعاليت فارماكولوزيك رادئ را دارد)،

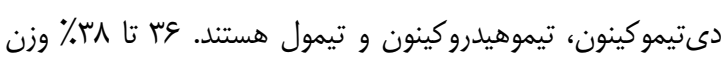

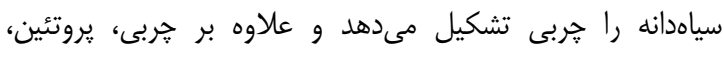
ويتامينها، مواد معدنى و كربوهيدراتها نيز در دانه سياهدانه وجود

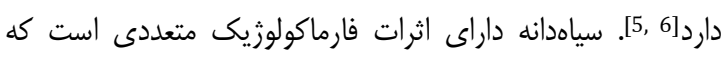
مىتوان به اثر آنتىاكسيدانى، ضدالتهابى، ضدآيويتوزى، تنظيم كنينده

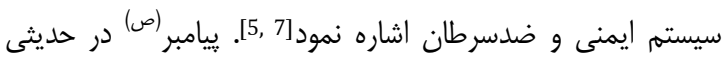
فرمودهاند: "بر شما باد مصرف سياهدانه كه همانا علاج تمام

$$
\text { بيمارىها بهجز مرگ در آن وجود دارد" [8]. }
$$

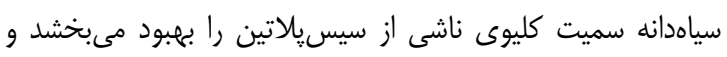

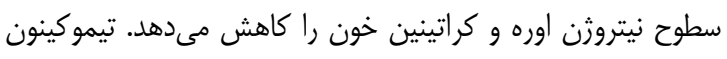
كه ماده موثره اصلى سياهدانه است، خاصيت آنتىاكسيدانى قوى نون داشته و كليهها را در برابر نفروياتى ناشى از دوكسوروبيسين و

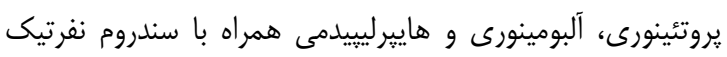

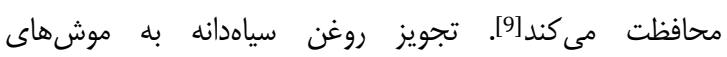

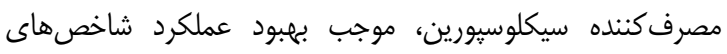

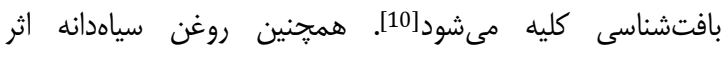
نفروتوكسيك جنتامايسين در موش را مهار مى كند[11].
اثر عصاره آبى- الكلى سياهدانى سنه بر آسيب

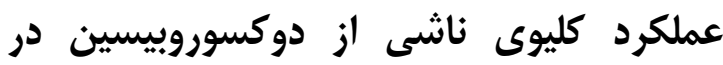
موشهاى صحر ايى MSc رضا محبتى كروه فيزيولوزى، دانشكده يزشكى، دانشخاه علوم يزشكى مشهد، مشهد، ايران عباسعلى عباسنزاد

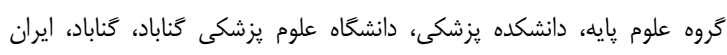

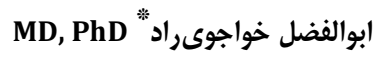
كروه فيزيولوزى، دانشكده يزشكى، دانشخاه علوم يزشكى مشهرد، مشهرد، ايران

سيدمجتبى موسوى MSc

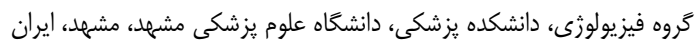
ميلاد حقشناس MSc كروه فيزيولوزى، دانشكده يزشكى، دانشخاه علوم يزشكى مشهد، مشهد، ايران جكيده اهداف: دوكسوروبيسين از داروهاى مهم ضدسرطان است كه باعث سميت كليوى مىشود. سياهدانه داراى اثرات ضدالتهابى و آنتىاكسيدانى دوانى

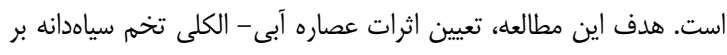
آسيب عملكرد كليوى ناشى از دوكسوروبيسين در موشهاى هاى صحرايى بود. مواد و روشها: در اين مطالعه تجربى، rس سر موش صحرايى نر نز دراد

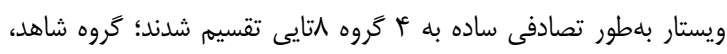

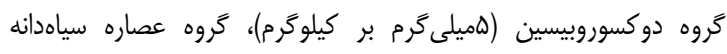

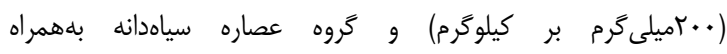

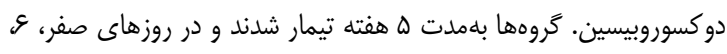

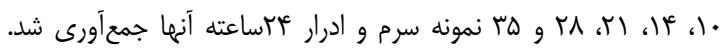

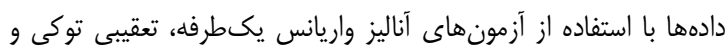
Tوزجى تحليل شدند.

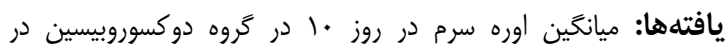

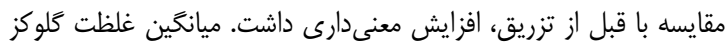

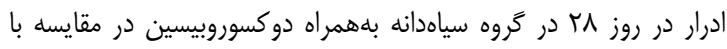

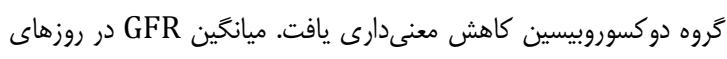

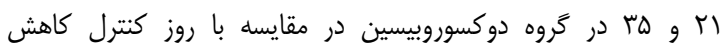

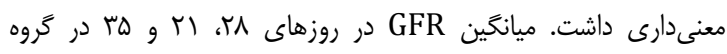

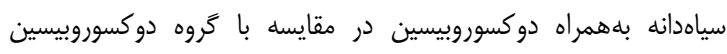

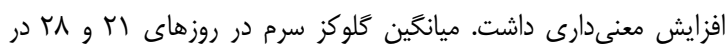

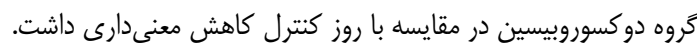

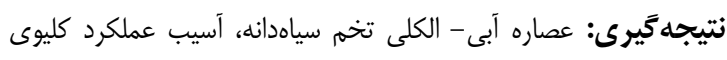

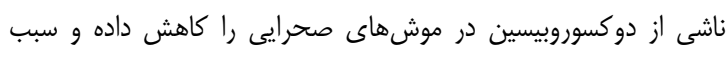

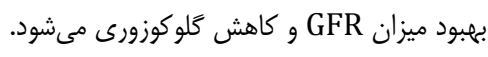

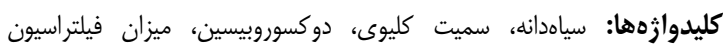

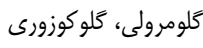

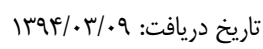

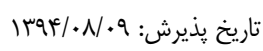
"نويسنده مسئول:khajavirada@mums.ac.ir 
اثر عصاره آبى - الكلى سياهدانه بر آسيب عملكرد كليوى ناشى از دوكسوروبيسين در موشهاى صحر ايیى 10

وريد دمى در روز هفتم مطالعه انجام شد.

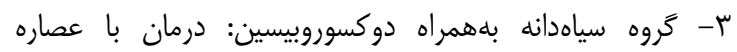

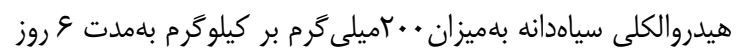

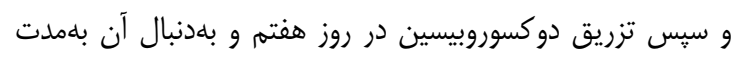

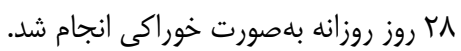

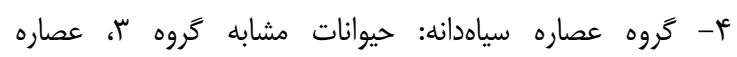

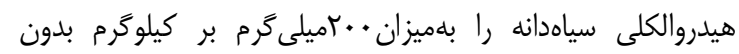
تزريق دوكسوروبيسين دريافت كردند.

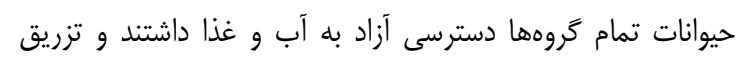

دوكسوروبيسين براى همه گروهها بلهروش داخل وريدى برى بود.

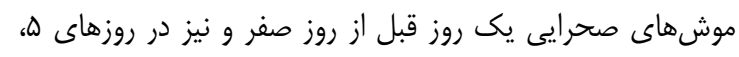

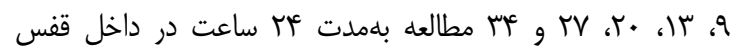

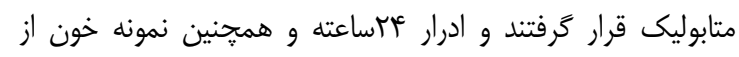

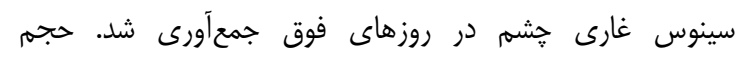

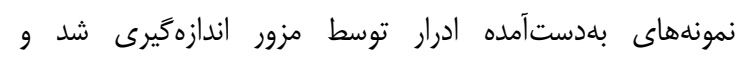

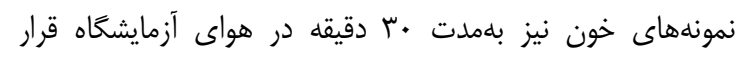

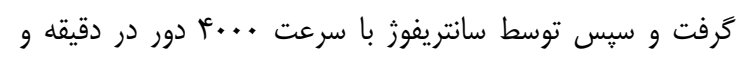
بلهمدت • 1 دقيقه، سرم از لخته خون جدا شد. نهايتاً نمونههاى ادرار

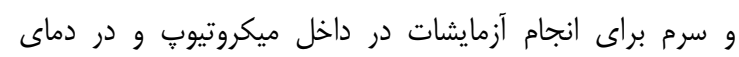

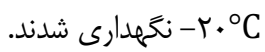
پِ از يايان دوره مطالعه و كشتن حيوانات بلهروش اخلاقى، بلن و كليه راست بلمنظور محاسبه ايندكس كليه توزين شدند.

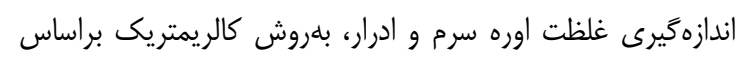
دستور كيت مربوطه (شركت بتاثن؛ ايران) و توسط دستعاه فتومتر

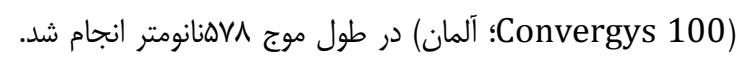
در روش مذكور، آمونياى حاصل از هيدروليز اوره، توسط آنزيم

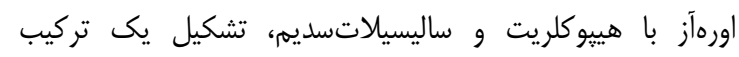
سبزرنگ مىدهد كه شدت رنتى ايجادشده متناسب با مقدار اوره در نمونه است[12]. محلولها طبق دستور شركت سازنده (يارس آزمون؛

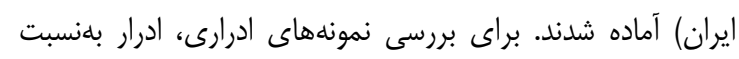

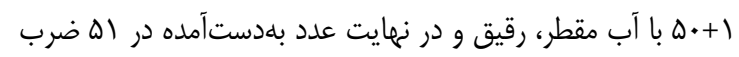

شد. اندازهيرى غلظت اوره سرم بدون رقيقسازى انجام شد.

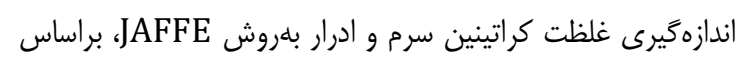
دستور كيت مربوطه (شركت بتازن؛ ايران) و توسط دستخاه فتومتر

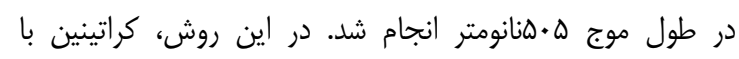

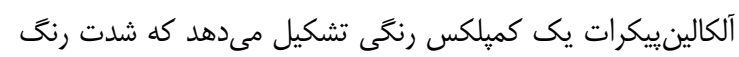
ايجادشده متناسب با مقدار كراتينين در نمونه است [14]. محلولها

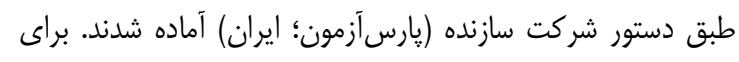

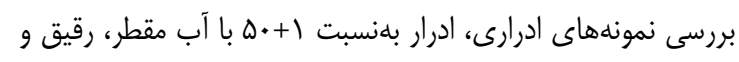

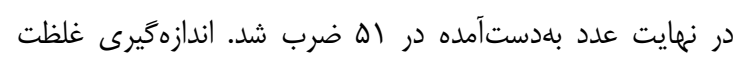
كراتينين سرم بدون رقيقسازى انجام شد.

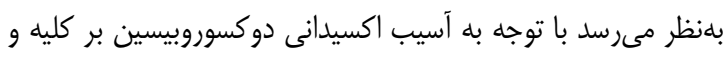

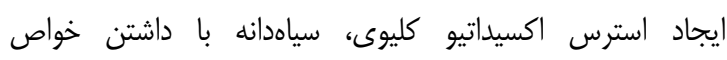

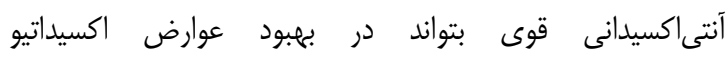

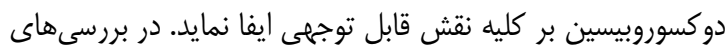

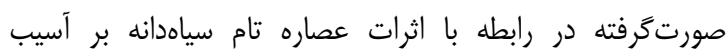
عملكردى كليوى ناشى از دوكسوروبيسين مطالعهاى مشاهده نشد.

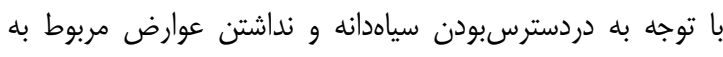
استفاده داروهاى شيمىدرمانى، در صورت مثبتبودن نتايج حاصل ماصل

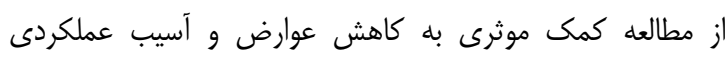

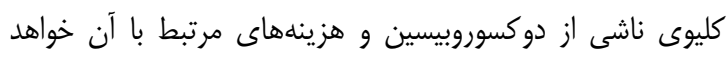

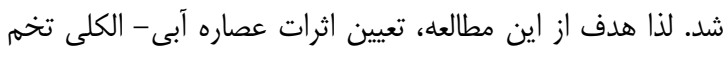

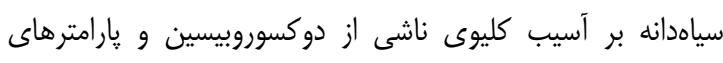
عملكردى كليه در موشهاى صحرايى بود.

\section{مواد و روشها}

اين مطالعه تجربى در سال سوسا در دانشخاه علوم يزشكى مشرهد

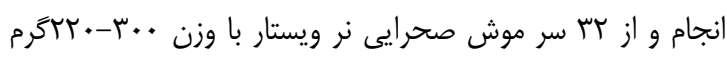

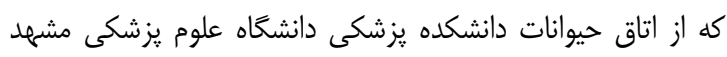

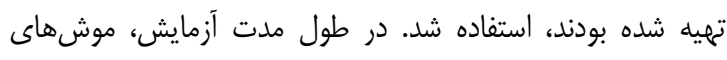

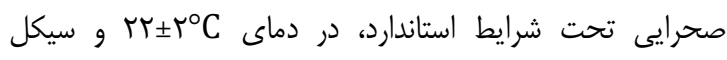

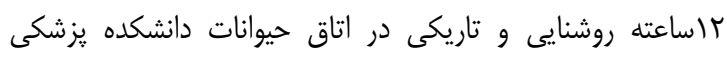

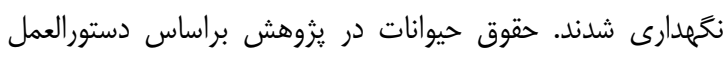

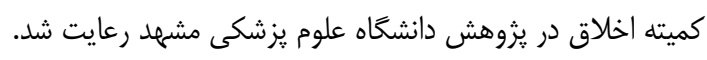
عصاره آبى - الكلى سياهدانه بلروش خيسانده تهيه شد. شئ ابتدا تخم

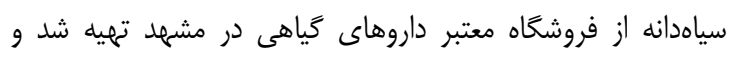
توسط متخصصان گياهشناسى دانشخاه فردوسى مشهر موردي مورد تاييد

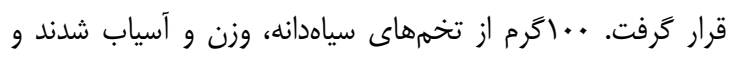

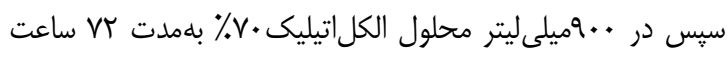

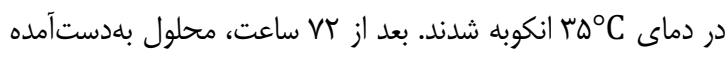

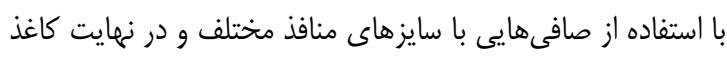
صافى، صاف شد. بdمنظور حذف حلال، محلول بهدستآمده در

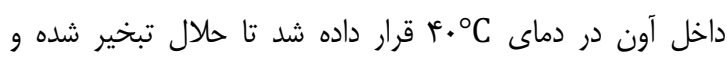

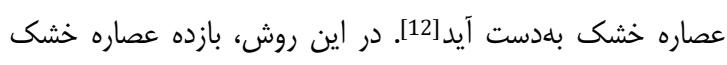

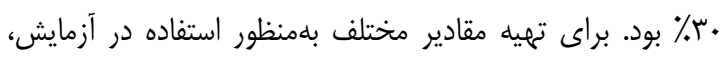
عصاره بلهدستأمده در آب مقطر حل شد. توديه موشهاى صحرايى بلهور تصادفى به أل خروه متايى تقسيم شدند:

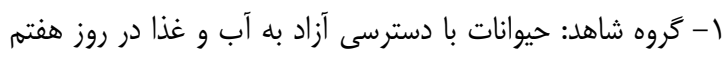
مطالعه معادل حجم مورد نياز براى تزريق دوكسوروبيسين، نرمالسالين بهروش تزريق داخل وريد دمى دريافت كردند.

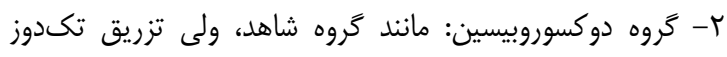

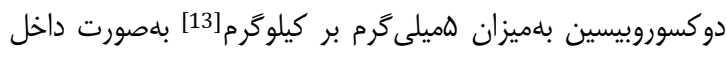


كروه كنترل و گروه دوكسوروبيسين با استفاده از آزمون آناليز

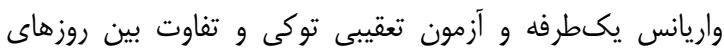

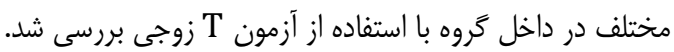

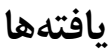

ميانكَين اوره سرم در روز •ا مطالعه در تروهاه دوكسوروبيسين در مقايسه با ميانگين روزهاى قبل از تزريق دوكسوروبيسين در دران همان

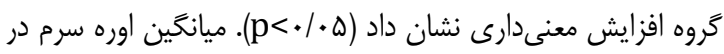

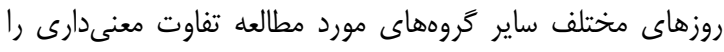

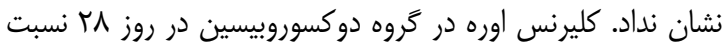

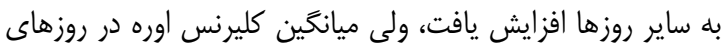

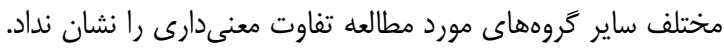

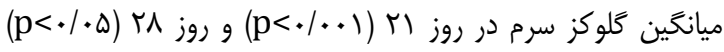

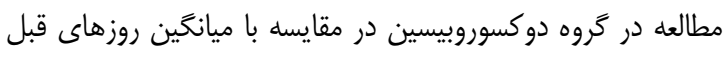

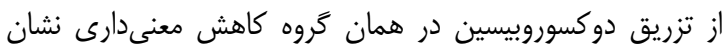

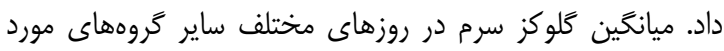
مطالعه تفاوت معنىدارى را نشان نداد (جدول ()).

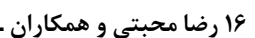

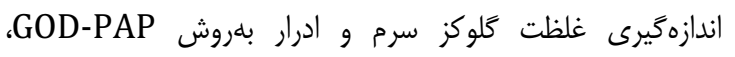
براساس دستور كيت مربوطه (شركت بتازن؛ ايران) و توسط دستكاه

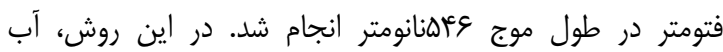

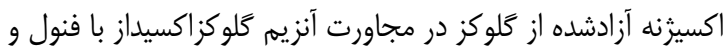

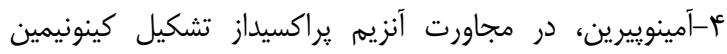

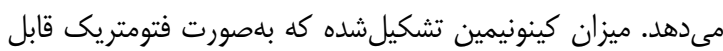

اندازمكيرى است، با مقدار كلوكز رابطه مستقيم دارد [12].

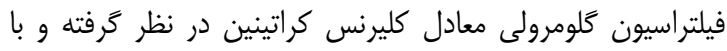

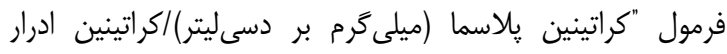

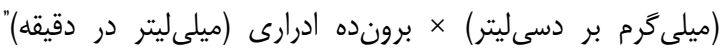

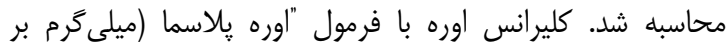

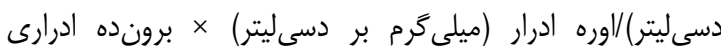

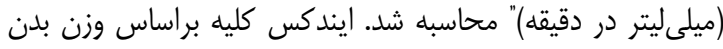

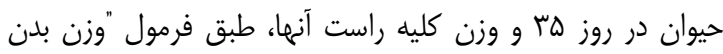

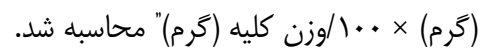

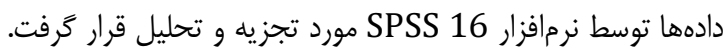

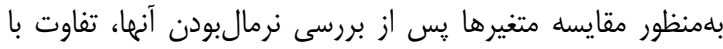

جدول () ميانكين اوره سرم، كليرنس اوره و كلوكز سرم در گروههاى مختلف مورد مطالعه (تعداد هر گروه لمسر) تحت تيمار عصاره آبى - الكلى تخم سياددانه

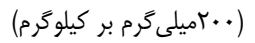

\begin{tabular}{|c|c|c|c|c|}
\hline 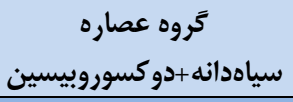 & سروه عصاره & دوكسوروبيسين & شاهد & 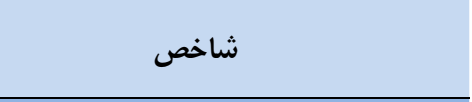 \\
\hline & & & & ميانكين اوره سرم (ميلى \\
\hline$\Delta \Delta / r \omega \pm r / M$ & $\Delta E / T T \pm T / \Lambda \varepsilon$ & $\mid \kappa / \cdot \varepsilon_{ \pm} \cdot / 8 \mu$ & $\Delta \cdot / 4 \cdot \pm 1 / \Delta 1$ & ميانگين روز صفر و \\
\hline$\Delta I / \wedge \varepsilon \pm 1 / / \Lambda$ & $\Delta r / r \Lambda \pm 1 / \kappa q$ & $G T / \cdot \Lambda \pm \cdot / V D^{*}$ & $\Delta T / F \Delta \pm T / K \varepsilon$ & 1. \\
\hline$\Delta r / \Delta r \pm 1 / q$. & $01 / 98 \pm 1 / 09$ & $F V / T^{\prime} \pm \cdot / V E$ & $\Gamma \& / \Lambda \Delta \pm r / r q$ & 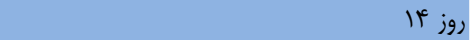 \\
\hline$|F / \wedge \varepsilon \pm r / r|$ & $\mid\{\wedge / \Delta ৭ \pm 1 / \wedge \mid$ & $\vdash \Delta / 1 \cdot \pm \cdot / q$. & DI/ATEY/rT & (روز إ ( \\
\hline$\Delta V / \mathcal{E q \pm} \pm T / \cdot \varepsilon$ & $0 \cdot / 91 \pm 1 / 94$ & $F \in / K \cdot \pm I / T F$ & $\Delta F / F+ \pm r / q V$ & 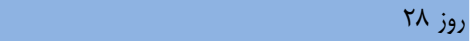 \\
\hline$\Delta F / 19 \pm F / \pi T$ & $\kappa r / V \Psi \pm \cdot / M$ & 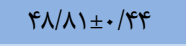 & $r \varepsilon / q T \pm r / R t$ & 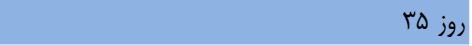 \\
\hline & & & & ميانكين كليرنس اوره (ميلىليتر در دقيقه) \\
\hline$\cdot / r \Lambda \pm \cdot / \cdot \Lambda$ & $\cdot / 4 q_{ \pm} \cdot / \cdot r$ & $\cdot \mid q_{ \pm} \cdot / I f$ & $\cdot / 4 V \pm \cdot 1 \cdot 9$ & ميانگين روز صفر و \\
\hline$\cdot / \mu \Lambda \pm \cdot / \cdot r$ & $\cdot / \mu \cdot \pm \cdot / \cdot \Delta$ & $\cdot / \mu \cdot \pm \cdot 1 \cdot 9$ & $\cdot / \& T \pm \cdot / 1 Q$ & 1. \\
\hline$\cdot / 4 q_{ \pm} \cdot / \cdot 4$ & $\cdot / 4 Q \pm \cdot / \cdot 0$ & $\cdot / V_{ \pm} \pm / / V$ & $\cdot / \mathbb{*} \Delta \pm \cdot / \cdot \Lambda$ & روز \\
\hline$\cdot / 8+ \pm \cdot 1 \cdot 9$ & $\cdot / r \Lambda \pm \cdot / \cdot \vee$ & $\cdot / 9 Y \pm \cdot / 1 \mathrm{~V}$ & $\cdot / 9 \cdot \pm \cdot / 1 \mathrm{~V}$ & روز إ إ \\
\hline$\cdot / \Delta T \pm \cdot / \cdot 1$ & $\cdot / 4 \Lambda \pm \cdot / \cdot r$ & $1 / r_{ \pm} \cdot / t \cdot$ & $\cdot / 4 \wedge \pm \cdot / I T$ & 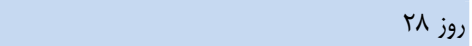 \\
\hline$\cdot / \Delta \mathrm{V} \pm \cdot / \cdot \mathrm{V}$ & $\cdot / r q \pm \cdot / 14$ & $\cdot / 9 \vee \pm \cdot / 1$ & $\cdot \mid \Delta H_{ \pm} \cdot 1 \cdot 9$ & 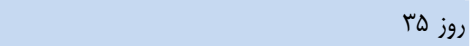 \\
\hline & & & & ميانَّين كَلوكز سرم (ميلى \\
\hline $\mid r \cdot / \Lambda \cdot \pm \Delta / F^{\prime} \Delta$ & $\mid r T / V \cdot \pm \Delta / \varepsilon \cdot$ & $\mid r \cdot / 4 \cdot \pm \cdot / \Delta T$ & $\mid r Q / 4 \cdot \pm V / 4 t$ & ميانگين روز صفر و \\
\hline$I r \cdot / V \cdot \pm r / r Q$ & $\mid r T / T \cdot \pm N / 9 V$ & $\mid T N / T \cdot \pm I / r \Delta$ & $\mid f \Phi / A \cdot \pm \Delta / W V$ & 1. \\
\hline $\mid f \Delta / r \cdot \pm r / \wedge q$ & $\mid \pi / 4 \cdot \pm 4 / 4 T$ & $\mid r / \Lambda \cdot \pm 1 / r 4$ & $\mid f \& / 4 \cdot \pm r / T$ & روز أ إ \\
\hline$I r \cdot / \Lambda \cdot \pm V / T V$ & $\mid r F / q \cdot \pm F / q V$ & $1 \cdot V / q \cdot \pm \cdot / \& \Upsilon^{\mu^{*}}$ & $\mid+4 / 1 \cdot \pm 9 / 4 \wedge$ & روز إ إ \\
\hline $1 \% \cdot 10 \cdot \pm 8 / 11$ & $\mid r / q \cdot \pm r / r V$ & $11 r / 9 \cdot \pm \cdot /\left.9\right|^{* * *}$ & $14 q / \cdot \cdots \pm 1 . / 94$ & 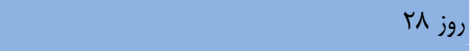 \\
\hline $1 K \cdot / D H_{ \pm}+r / r g$ & $|r / / R \cdot \pm| r / \Lambda \mid$ & $\mid \pi d / 1 \cdot \pm t / . t$ & $11+1 \cdots \pm 9 / 9 V$ & 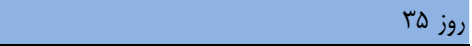 \\
\hline
\end{tabular}

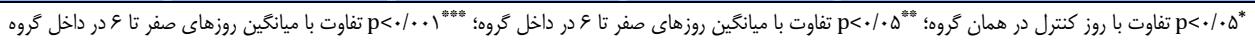



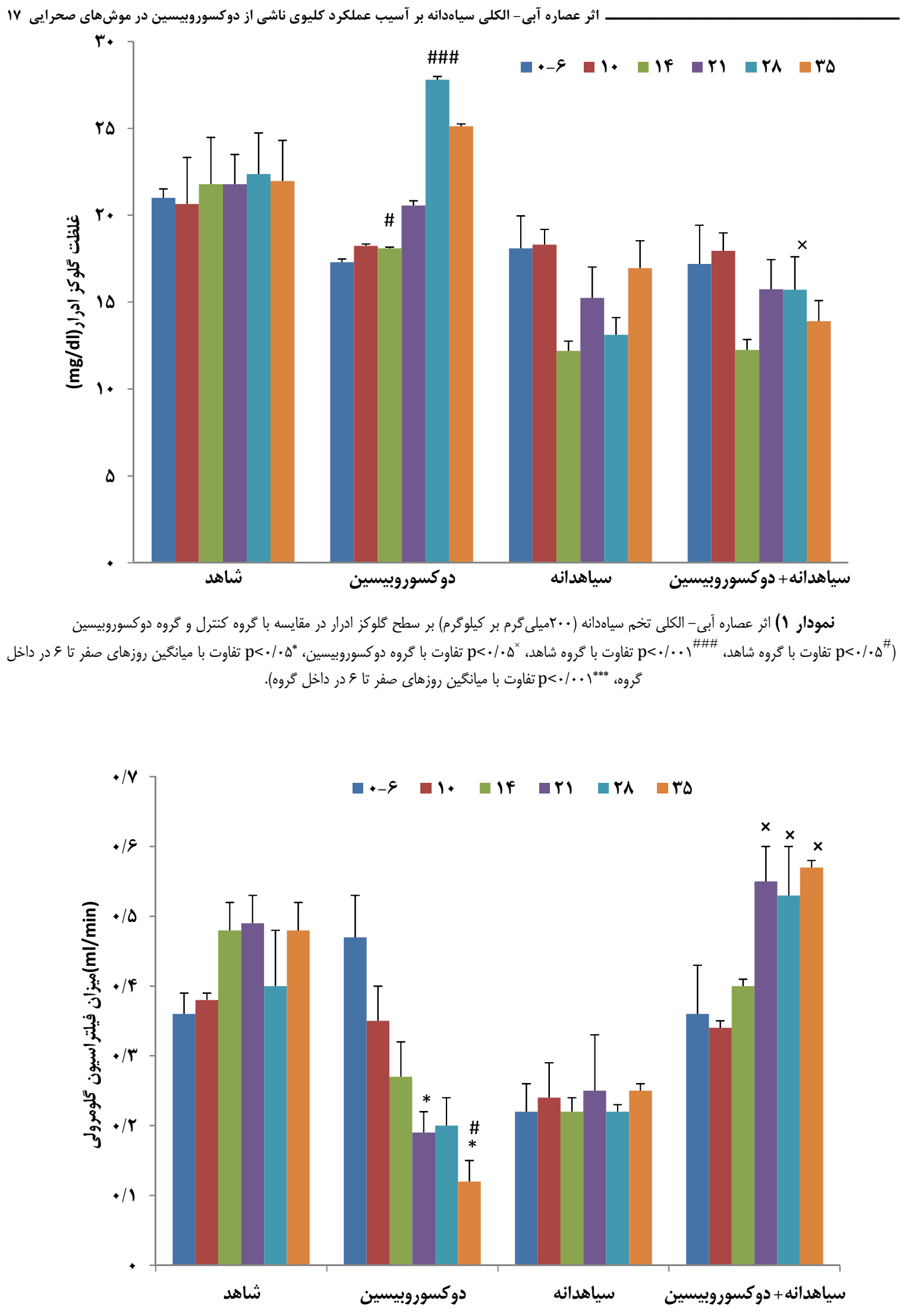

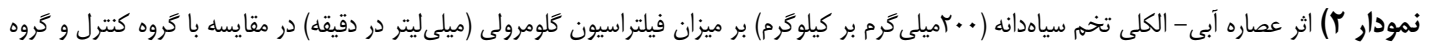

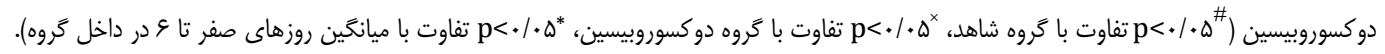


سميت كليوى مى شود. مكانيزمهاى متعددى در اين زمينه مطرح

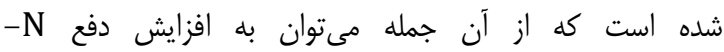

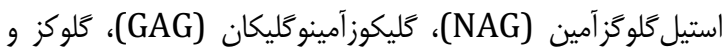
فيبرونكتين از ادرار، كاهش سرعت فيلتراسيون كلومرولى (GFR)

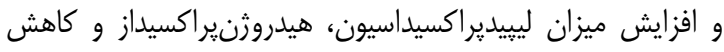
ميزان آنزيمهاى أنتىاكسيدان، اشاره نمود [16]. در مطالعه ديكرى نيز تزريق داخل وريدى دوبار دوكسوروبيسين

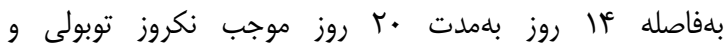

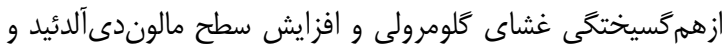

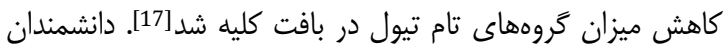

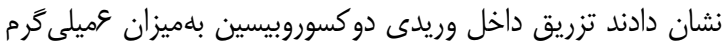

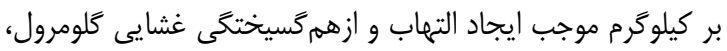

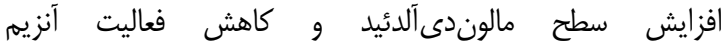

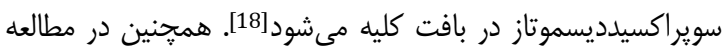
ديخرى تجويز دوكسوروبيسين موجب ايجاد اسكلروز گلومرولى و

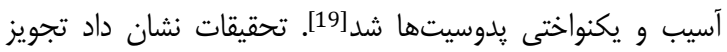
داخل وريدى دوكسوروبيسين موجب ازهم كسيختكى و كاهش تعداد

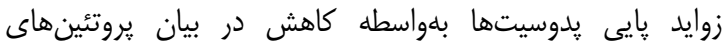

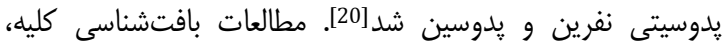
تخريب كليوى را در تروه دوكسوروبيسين تاييد مى كنند. مطالعات

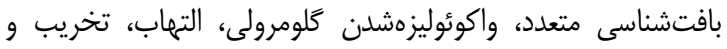

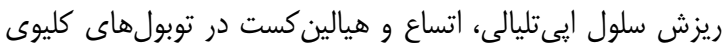

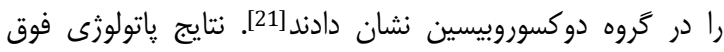

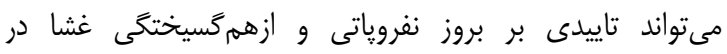
كلومرولهاى كليه باشد.

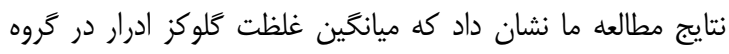
سياهدانه بههمراه دوكسوروبيسين در مقايسه با گروه دوكسوروبيسين

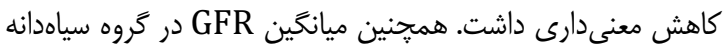

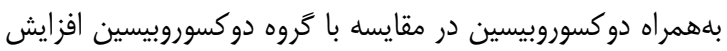

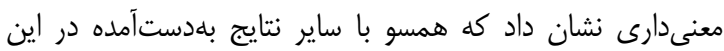

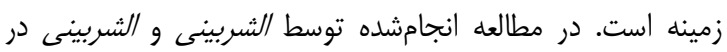

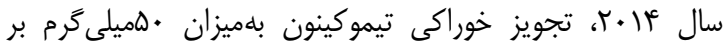

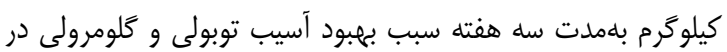
بافت كليه آسيبديده توسط دوكسوروبيسين شد [22]. در مطالعات كَونامون به خواص ضدالتهابى و آنتى اكسيدانى سياهدانه و تيموكينون بلعنوان يكى از مهمترين مواد موثره سياهدانه اشاره

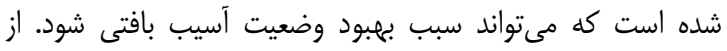

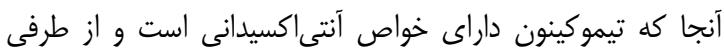

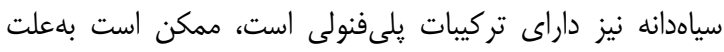

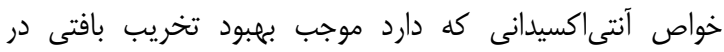

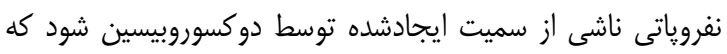

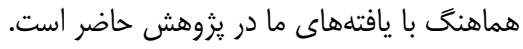

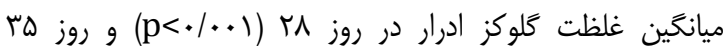

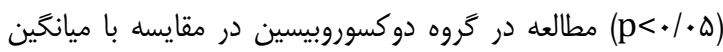

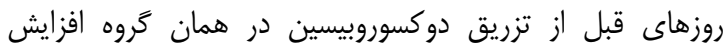

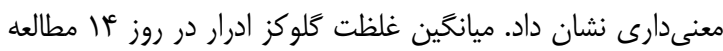

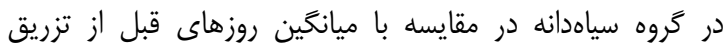

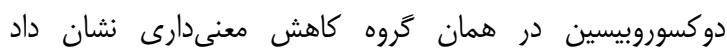

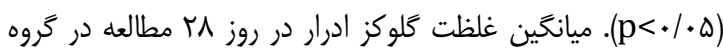

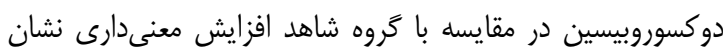

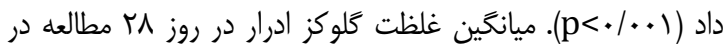

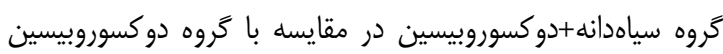

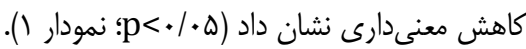

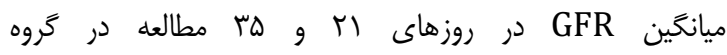

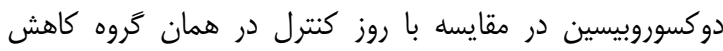

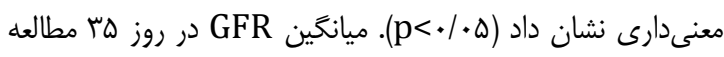
در گروه دوكسوروبيسين در مقايسه با گروه شاهد نيز كاهش

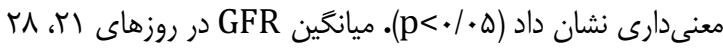

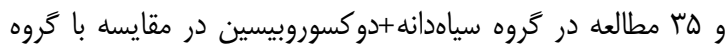

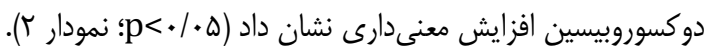

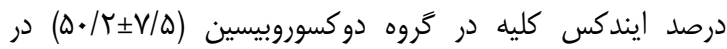

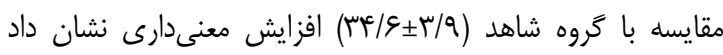

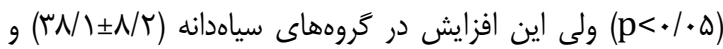

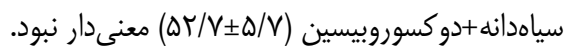

\section{بحث}

نتايج مطالعه حاضر بهطور مشخصى نشان داد كه در كروه

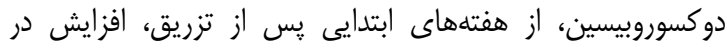

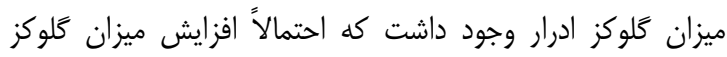

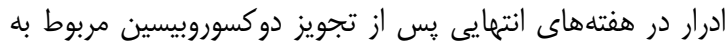

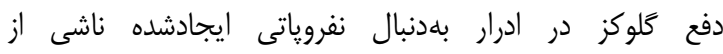
دوكسوروبيسين است. تجويز عصاره سياهدانه بهاهمراه دوكسوروبيسين موجب كاهش ميزان كلوكز ادرار در هفتينه إنهاى

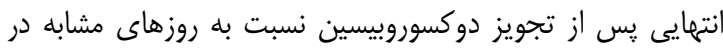

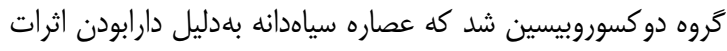

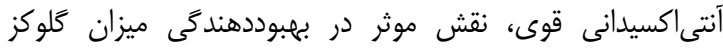

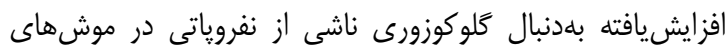
صحر ايى تيمارشده با دوكسوروبيسين داشت.

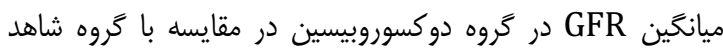
كاهش معنىدارى داشت كه اين نتايج همسو با نتايج ساير مطالعات

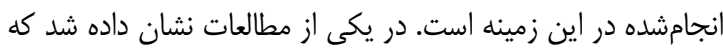

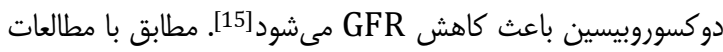
قبلى، در اين مطالعه نشان داده شد كه دوكسوروبين بانيسين موجب 


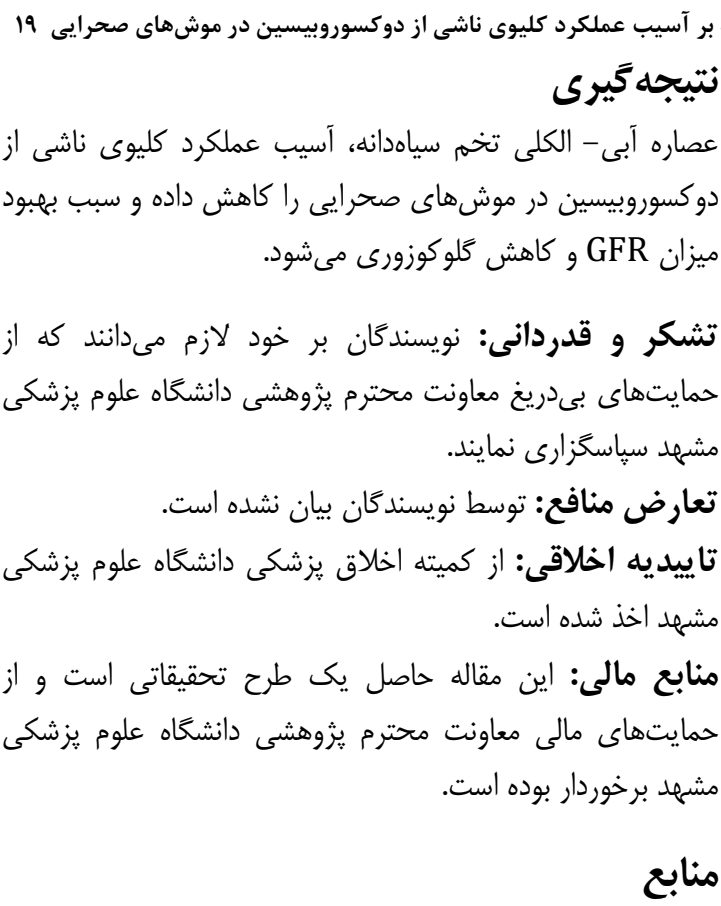

1- Lee VW, Harris DC. Adriamycin nephropathy: A model of focal segmental glomerulosclerosis. Nephrol. 2011;16(1):30-8.

2- Balakumar P, Chakkarwar VA, Kumar V, Jain A, Reddy J, Singh M. Experimental models for nephropathy. J Renin Angiotensin Aldosterone Syst. 2008;9(4):189-95.

3- Jeansson M, Björck K, Tenstad 0 , Haraldsson B. Adriamycin alters glomerular endothelium to induce proteinuria. J Am Soc Nephrol. 2009;20(1):114-22.

4- Venkatesan N, Punithavathi D, Arumugam V. Curcumin prevents adriamycin nephrotoxicity in rats. $\mathrm{Br}$ J Pharmacol. 2000;129(2):231-4.

5- Ali BH, Blunden G. Pharmacological and toxicological properties of Nigella sativa. Phytother Res. 2003;17(4):299-305.

6- Salem ML. Immunomodulatory and therapeutic properties of the Nigella sativa L. seed. Int Immunopharmacol. 2005;5(13-14):1749-70.

7- Boskabady MH, Shirmohammadi B, Jandaghi P, Kiani S. Possible mechanism(s) for relaxant effect of aqueous and macerated extracts from Nigella sativa on tracheal chains of guinea pig. BMC Pharmacol. 2004;4:3.

8- Randhawa MA. Black seed, Nigella sativa, deserves more attention. J Ayub Med Coll Abbottabad. 2008;20(2):1-2.

9- Gilani A-uH, Jabeen Q, Allah Khan MA. A review of medicinal uses and pharmacological activities of Nigella sativa. Pak J Biol Sci. 2004;7(4):441-51.

10- Uz E, Bayrak O, Kaya A, Bayrak R, Uz B, Turgut FH, et al. Nigella sativa oil for prevention of chronic cyclosporine nephrotoxicity: An experimental model. Am J Nephrol. 2008;28(3):517-22.

11- Yaman I, Balikci E. Protective effects of Nigella sativa against gentamicin-induced nephrotoxicity in rats. Exp Toxicol Pathol. 2010;62(2):183-90.

12- Burtis C, Ashwood E, Bruns D. Tietz textbook of clinical chemistry and molecular diagnostics. New York: Elsevier Health Sciences; 2015.
در بررسى حاضر، افزايش معنىدار ايندكس كليه در زروه

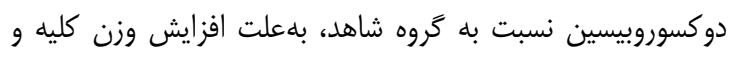

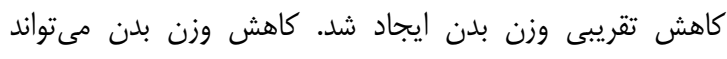

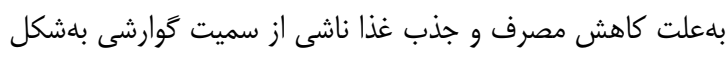
تهوع، استفراغ و اسهال ايجاد شود. افزايش وزن كليه مىتواند ناشى از ادم بافتى و تجمع مايع در فضاى ميانبافتى كليه بلهدليل افزايش

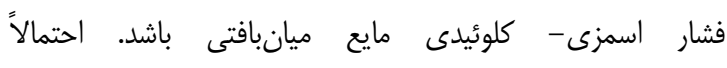
دوكسوروبيسين با اثرات اكسيداتيو خود موجب آسيب سلولهاى

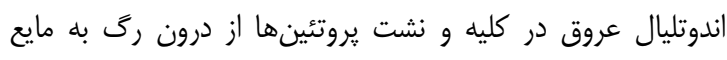

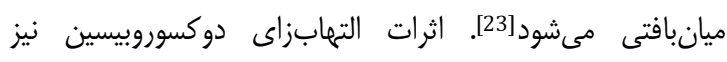
مىتواند منجر به ايجاد التهاب و افزايش وزن دئ در بافت كليه شده و

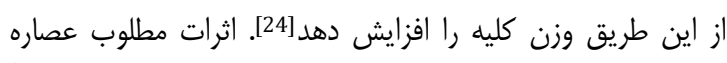
سياهدانه بر افزايش ايندكس كليوى ناشى از دوكسوروبيسين احتمالاً مىتواند بهدليل اثرات متعدد آن از جمله خواص آنتى آنى اكسيدانى،

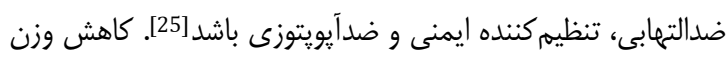
بدن و كليه در مدلهاى حيوانى تزريق دوكسوروبيسين در مطالعه تهنيه

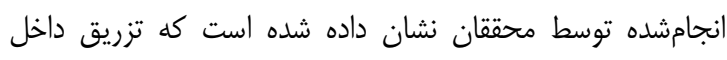

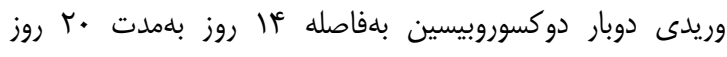

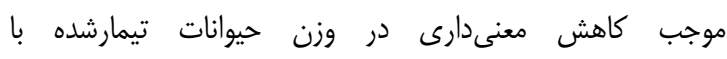

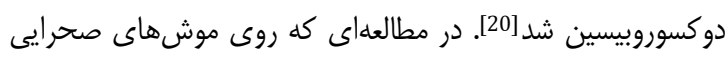
صورت گرفت مشخص شد كه تجويز دوكسوروبيسين سبب كاهش

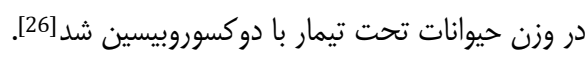

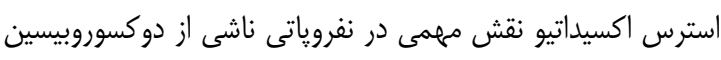

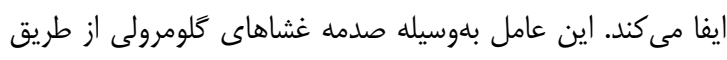

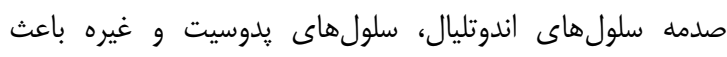
نفروياتى مىشود. مطالعات زيادى انجام شده كه نشان مى مدهد دوكسوروبيسين روى آنزيمهاى استرس اكسيداتيو تاثير دارد[27].

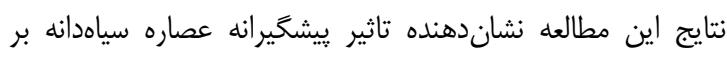
فعاليت اكسيدانى دوكسوروبيسين در بافت كليه بود. علت خواص آنتىاكسيدانى عصاره سياهدانه ممكن است مربوط به به وجود مواد دوراد

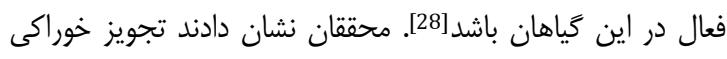

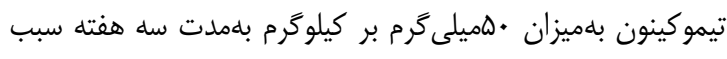

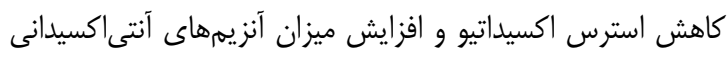

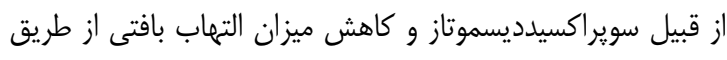
كاهش توليد

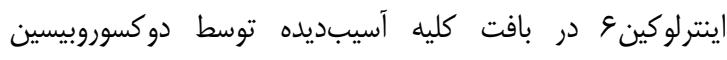
شد [22]. از محدوديتهاى اين مطالعه زمانبربودن تهيه عصاره سياهدانه

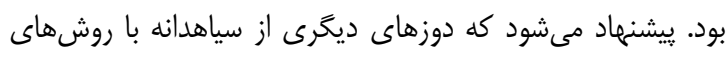
تجويز و دورههاى زمانى متفاوت نيز كار شود. 
rats: An experimental research. Zhongguo Zhong Xi Yi Jie He Za Zhi. 2014;34(2):203-8.

21- Wei M, Sun W, He W, Ni L, Cai X, Cheng Z, et al. Qiguiyishen decoction reduced the accumulation of extracellular matrix in the kidneys of rats with adriamycin-induced nephropathy. J Tradit Chin Med. 2014;34(3):351-6.

22- Elsherbiny NM, El-Sherbiny M. Thymoquinone attenuates Doxorubicin-induced nephrotoxicity in rats: Role of Nrf2 and NOX4. Chem Biol Interact. 2014;223C:102-8.

23- Hommel E, Mathiesen ER, Aukland K, Parving HH. Pathophysiological aspects of edema formation in diabetic nephropathy. Kidney Int. 1990;38(6):1187-92.

24- You H, Lu Y, Gui D, Peng A, Chen J, Gu Y. Aqueous extract of Astragali Radix ameliorates proteinuria in adriamycin nephropathy rats through inhibition of oxidative stress and endothelial nitric oxide synthase. J Ethnopharmacol. 2011;134(1):176-82.

25- Kawamori T, Lubet R, Steele VE, Kelloff GJ, Kaskey $\mathrm{RB}, \mathrm{Rao} \mathrm{CV}$, et al. Chemopreventive effect of curcumin, a naturally occurring anti-inflammatory agent, during the promotion/progression stages of colon cancer. Cancer Res. 1999;59(3):597-601.

26- Franco R, Gut A, Ferrari-Spadotto A, Georgette J, Gavras I, Gavras H. Pressor mechanisms in adriamycininduced nephropathy with hypertension in rats. Hypertens. 1994;23(1):246-9.

27- Koul A, Shubrant S, Gupta P. Phytomodulatory potential of lycopene from Lycopersicum esculentum against doxorubicin induced nephrotoxicity. Indian J Exp Biol. 2013;51(8):635-45.

28- Jadhav VB, Thakare VN, Suralkar AA, Naik SR. Ameliorative effect of Luffa acutangula Roxb. on doxorubicin induced cardiac and nephrotoxicity in mice. Indian J Exp Biol. 2013;51(2):149-56.

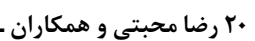

13- Zima T, Tesar V, Crkovska J, Stejskalová A, Platenik J, Teminova J, et al. ICRF-187 (dexrazoxan) protects from adriamycin-induced nephrotic syndrome in rats. Nephrol Dial Transplant. 1998;13(8):1975-9.

14- Chromý V, Rozkošná K, Sedlak P. Determination of serum creatinine by Jaffe method and how to calibrate to eliminate matrix interference problems. Clin Chem Lab Med. 2008;46(8):1127-33.

15- Montilla P, Tunez I, Munoz MC, Lopez A, Soria JV. Hyperlipidemic nephropathy induced by adriamycin: effect of melatonin administration. Nephron. 1997;76(3):345-50.

16- Di Marco A, Arcamone F, Zunino F. Daunomycin (daunorubicin) and adriamycin and structural analogues: biological activity and mechanism of action. In: Corcoran JW, Hahn FE. Mechanism of Action of Antimicrobial and Antitumor Agents Antibiotics. New York: Springer Science \& Business Media; 2012.

17- Sarhan M, El Serougy H, Hussein AM, El-Dosoky M, Sobh MA, Fouad SA, et al. Impact of bone-marrowderived mesenchymal stem cells on adriamycin-induced chronic nephropathy. Can J Physiol Pharmacol. 2014;92(9):733-43.

18- Liang $\mathrm{Cl}$, Wu Jb, Lai J, Ye S, Lin J, Ouyang $\mathrm{H}$, et al. Protection effect of Zhen-Wu-Tang on AdriamycinInduced Nephrotic syndrome via inhibiting oxidative lesions and inflammation damage. Evid Based Complement Altern Med. 2014;2014:1-11.

19- Zhu C, Xuan X, Che R, Ding G, Zhao M, Bai M, et al. Dysfunction of the PGC-1alpha-mitochondria axis confers adriamycin-induced podocyte injury. Am J Physiol Renal Physiol. 2014;306(12):1410-7.

20- Wang Z, Liu JT, Sun WS, Li RP, Wang Y. Effect of Qufeng Tongluo Recipe on expression of desmin and CD2AP proteins in adriamycin-induced nephropathy 